\title{
LA «CIUDAD MODERNA» EN LA HABANA
}

\author{
Gabino Ponce Herrero \\ Departamento de Geografía Humana \\ Universidad de Alicante
}

\section{RESUMEN}

La Habana transitó por las décadas centrales de la primera mitad del siglo XX sin un verdadero plan de ordenación urbana, pese a un fuerte crecimiento demográfico que pasó desde los 446.848 habitantes de 1919 hasta los 1.528 .800 habitantes de 1960. Pese a los intentos reguladores, las dinámicas del mercado del suelo e inmobiliario tomaban carta de naturaleza en una ciudad que proseguía su imparable crecimiento a impulsos individuales, de la mano de un urbanismo especulativo, supeditado a la expansión suburbana sin límites. La ciudad que deseaba alcanzar una imagen cosmopolita y contemporánea, elegía las propuestas del Movimiento Moderno para definir su nueva morfología urbana y, con ella, expresar su emergente estructura social y económica. Influenciado por los CIAM, en 1954 se formulaba la Carta de La Habana. En 1955 la Junta Nacional de Planificación contrataba a Wiener y Sert para diseñar diversos planes urbanísticos para la puesta en valor turístico de Varadero y La Habana del Este, así como para redactar el nuevo Plan Director de La Habana. La Revolución supuso el freno a las propuestas de reforma interna, pero desarrolló las ideas de La Habana del Este.

Palabras clave: Movimiento Moderno, racionalismo, La Habana.

\section{ABSTRACT}

The city of Havana lived through the mid- $20^{\text {th }}$ century with no real urban planning project, despite significant demographic growth that saw the population rise from 446,848 in 1919 to $1,528,800$ in 1960 . Although efforts were made to control the situation, the dynamics of the land and property development markets were regarded as normal and accepted unconditionally in a city that continued its relentless growth on the basis of individual impulses allied with speculative town planning and unlimited suburban expansion. The city wished to build a cosmopolitan, contemporary image and chose Modern Movement proposals to define its new urban morphology and thus express its emerging social and economic structure. Influenced by the CIAM movement, the Carta de La Habana (The Havana Treaty) was drafted in 1954. In 1955, the Junta Nacional de Planificación (National Planning Commission) commissioned Wiener and Sert to draw up various town planning schemes to boost tourism in Varadero, Trinidad, Isla de Pinos 
and Eastern Havana, as well as drafting the new Plan Director de La Habana (Havana Master Plan). The Revolution slowed efforts for internal reform but implemented the Eastern Havana ideas.

Key words: Modern Movement, rationalism, Havana.

La ciudad de La Habana transitó por las décadas centrales de la primera mitad del siglo XX sin un verdadero plan de ordenación urbana. Precisamente, en una etapa de fuerte crecimiento demográfico: la ciudad, que contaba con 446.848 habitantes en 1919, llegaba hasta el 1.528.800 habitantes de 1960. Pese a los intentos reguladores, las dinámicas del mercado del suelo e inmobiliario tomaban carta de naturaleza en una ciudad que proseguía su imparable crecimiento a impulsos individuales, de la mano de un urbanismo especulativo, supeditado a la expansión suburbana, posible para un segmento social por la generalización del automóvil y, para otro segmento social por la difusión de los transportes colectivos. El acceso a esos medios de locomoción seguía imponiendo la segregación social conforme con las grandes directrices observadas con anterioridad: barrios obreros por el interior desde el foco industrial de la bahía, urbanizaciones elitistas en la línea de costa, y repartos para clases medias entre uno y otro vector. Por su parte, el sector servicios crecía de acuerdo con la importancia de su tradición y a expensas de la nueva capitalidad. También crecían las iniciativas turísticas y la paulatina orientación de ese nuevo segmento económico hacia el turismo cautivo en casinos. El turismo contribuía a paliar la endémica dependencia de la economía habanera (y aún cubana) de las exportaciones de azúcar, si bien, los negocios turbios e ilícitos generados a su alrededor contribuyeron a su desprestigio y a la consolidación de la leyenda negra ${ }^{1}$ de un sector ahora emergente.

\section{De la Carta de Atenas a la Carta de La Habana}

En ese nuevo contexto de apertura económica e integración paulatina en el sistema capitalista mundial, la ciudad que deseaba alcanzar de una vez una manifiesta imagen cosmopolita y contemporánea, elegía las propuestas del Movimiento Moderno para definir su nueva morfología urbana y, con ella, expresar su emergente estructura social y económica. Para entender mejor los planes modernos para La Habana, es preciso señalar que las primeras propuestas de Le Corbusier recogen que en la ciudad contemporánea cada segmento social ocuparía un lugar específico, segregado, conforme con su poder adquisitivo: la vivienda dependería del trabajo de cada uno (Fishman, 1982: 199); y su reparto espacial sería reflejo de una estructura social diferenciada. En La Ville contemporaine (1922) y en La Ville radieuse (1933) proponía una ciudad funcional, con diferentes espacios diseñados para acoger, cada uno de ellos, una actividad específica. En esa segregación de funciones, el centro urbano debía remodelarse para acoger la función de centro de negocios y servicios de carácter extraordinario. Pero los centros históricos, como el de La Habana, no reunían las condiciones adecuadas para las exigencias de la sociedad moderna y, por consiguiente, debían ser demolidos y surcados por grandes avenidas que potenciasen su centralidad y accesibilidad (Le Corbusier, 1929).

En 1935 se edita la Carta de Atenas como manifiesto de las ideas del grupo de urbanistas integrados en los Congresos Internacionales de Arquitectura Moderna (CIAM), ideas que fueron adoptadas como modelo para muchas ciudades latinoamericanas en los

1 Conocidas son las vinculaciones mafiosas y el blanqueo de dinero en los diferentes casinos habaneros. 


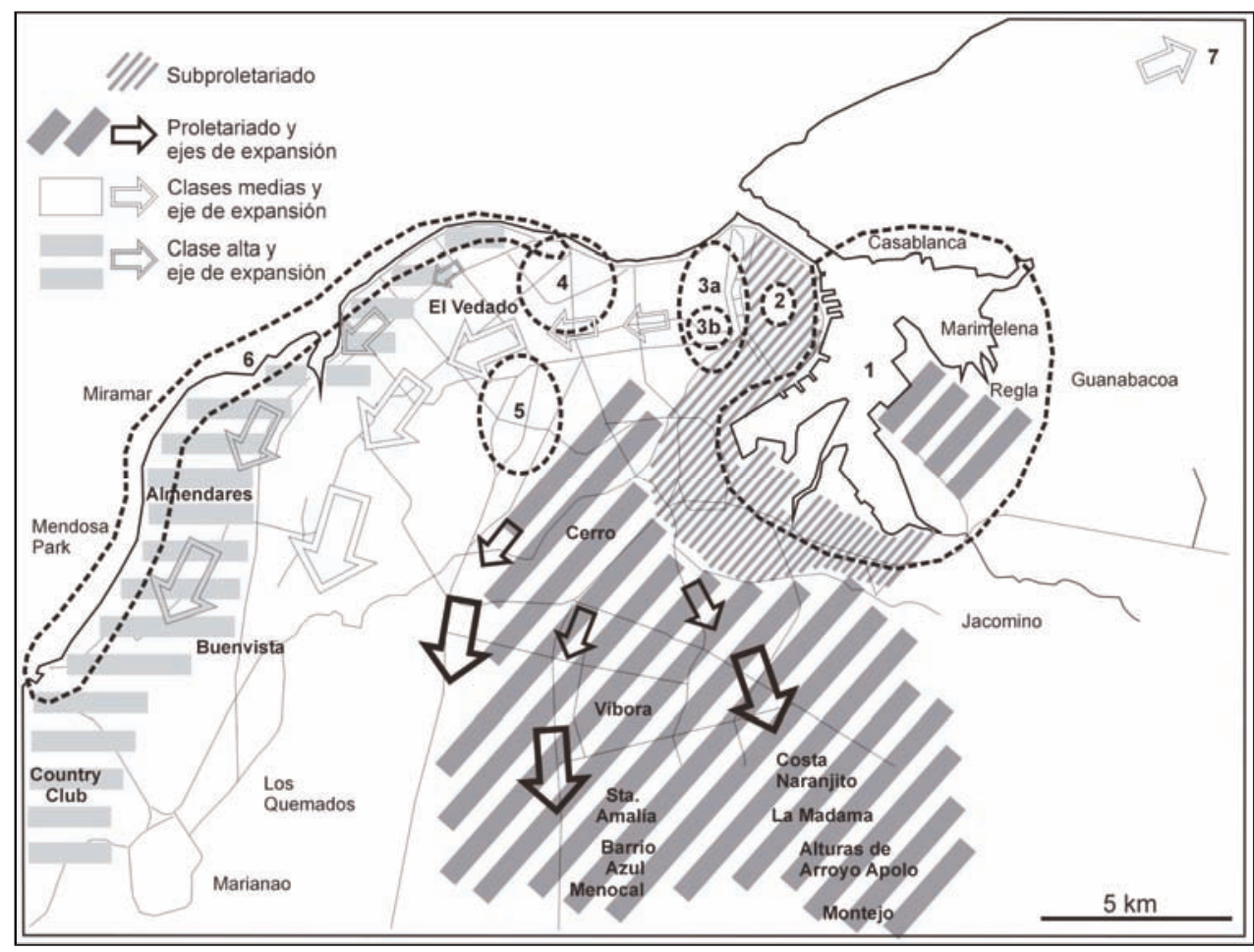

Figura 1. Usos del suelo y clases socioeconómicas en La Habana de mediados del s. XX: 1, zona de actividades portuarias; 2 , centro financiero; $3 \mathrm{a}$, centro comercial y de negocios; $3 \mathrm{~b}$, Barrio Chino; 4, nuevo centro funcional de la ciudad; 5, centro cívico promovido por la Administración; 6, frente turístico clases altas; 7, frente turístico clases medias Playas del Este (dibujo G. Ponce).

años 1950 (planes de Buenos Aires, Bogotá y Brasilia entre otros). De hecho, en 1954 Martínez Inclán, arquitecto municipal de La Habana, formulaba la Carta de La Habana, como manifiesto de denuncia de los graves problemas arrastrados por una desbordante ciudad, cuyo crecimiento obedecía casi en exclusiva a las leyes del mercado. Martínez Inclán ajustaba su preocupación social a los nuevos principios socializantes redefinidos por Le Corbusier y su grupo teórico, plasmados en la Unité d'habitation, vivienda inserta en grandes bloques levantados sobre supermanzanas con jardines y equipamientos colectivos, complementarios de los servicios del hogar. Conforme con el paradigma racionalista, el centro de La Habana debía albergar a la «ciudad comercial radioconcéntrica», mientras las demás funciones debían redistribuirse de forma estratégica por el territorio: la industria formando ejes a lo largo de las principales vías de comunicación y en sus alrededores las viviendas para los trabajadores, mientras que en los intersticios no urbanizados debían establecerse explotaciones agrícolas, con viviendas rurales. Se reproducían en La Habana los tres establecimientos humanos, conectados por medio de grandes autopistas u otros sistemas de transporte colectivo (Le Corbusier, 1945).

Martínez Inclán y otros urbanistas cubanos asumieron las propuestas del Movimiento Moderno como la solución necesaria para una ciudad que alcanzaba rango metropolitano: la planificación debía ser un programa de acción organizado específicamente para conse- 
guir unos objetivos precisos, definidos a partir de la identificación de unas necesidades concretas.

En opinión de Le Corbusier, todos los aspectos relacionados con el urbanismo estarían recogidos en un plan integral, elaborado por los expertos de forma objetiva, lejos de toda presión o interés. Pero esa misma voluntad de alejamiento y pureza es la que llevó a las propuestas modernas a alejarse de la voluntad ciudadana y, también, a separarse del contexto urbano que debían corregir, levantando con frecuencia nuevos escenarios urbanos carentes de humanidad y descontextualizados. El urbanista experto es quien tenía la respuesta para todos los problemas de la ciudad, al margen de la opinión de los ciudadanos e, incluso, de sus representantes políticos (Hall, 1998: 216-250). En 1953, los urbanistas cubanos Martínez Inclán, Weis, De Soto, Cayado, Cañas Abril y Sorhegui (Segre, Cárdenas, Aruca: 1986: 213) exponían así esa preocupación:

«La función social del arquitecto es la de asumir la responsabilidad de coadyuvar junto y en colaboración estrecha con todos los técnicos y especialistas necesarios, en la solución de los graves y serios conflictos con los que se enfrentan hoy nuestros pueblos, especialmente en el aspecto de la habitación, ubicando sus actividades por dentro de las normas de una planificación integral».

\section{El Plan Director de Sert y Wiener}

En ese ambiente intelectual «moderno» y en un contexto económico que veía en el turismo una fuente de ingresos y divisas complementaria a las exportaciones de azúcar, la dictadura de Batista promulgó, en 1955, la Ley de Planificación Nacional, mediante la cual se creaba la Junta Nacional de Planificación. Ese mismo año se contrataba al grupo norteamericano Town Planning Asociates integrado entre otros por Paul Lester Wiener, José Luis Sert, Paul Schulz y Mario Romañach, para diseñar diversos planes urbanísticos para la puesta en valor turístico de Varadero, Trinidad, Isla de Pinos y La Habana del Este, así como para redactar el nuevo Plan Director de La Habana.

El área metropolitana contaba, en esos momentos, con unos 1.400 .000 habitantes, pero el plan establecía cauces para acoger crecimientos futuros fijados en un horizonte de 4 millones de personas, conforme con los altos ritmo de crecimiento experimentados. De ese modo, el solar municipal resultaba insuficiente y era preciso desbordar el marco de planificación a toda la provincia, conforme con las teorías de la planificación regional difundidas en Gran Bretaña y en los Estados Unidos, y que se plasmaría en el plan de Abercrombie, en 1944, para el Gran Londres: un centro urbano para actividades terciarias, limitado en su crecimiento por un cinturón verde y, más allá, una constelación de ciudades satélites para albergar la actividad industrial y, entre ellas, los asentamientos rurales, todo configurando un sistema urbano integrado, articulado por una densa red de autopistas y ferrocarriles.

Muy semejante es el esquema formal propuesto por Sert y Wiener para La Habana, que mantenía la esencia de los tres establecimientos humanos de Le Corbusier. Con el objetivo de cumplir una necesidad arrastrada desde principios de siglo, el nuevo plan pretendía recrear nuevos escenarios ciudadanos, que elevasen el rango urbano de La Habana al de una nueva capital de un nuevo Estado, plenamente inserto, además, en un sistema económico internacional. La nueva morfología debía también potenciar el emergente negocio turístico, conforme con las tendencias del momento y la fuerte especialización habanera en turismo de casino, si bien la oferta se complementaba en el plan con el producto de «sol y playa» ofrecido por la puesta en valor de las Playas del Este y Varadero, insertas en el plan regional metropolitano. De ese modo, todo el centro urbano se planificaba con los objetivos precisos 
de, por un lado, recuperar la centralidad social, económica y simbólica, aspectos diluidos ante el enorme crecimiento suburbano de La Habana y, por otro lado, recuperar escenarios coloniales — La Habana Vieja - y ponerlos al servicio del turismo.

Conciliar ambos intereses en un espacio urbano densamente ocupado suponía, conforme con las ideas modernas, esponjar el tejido urbano a costa de demoliciones selectivas, para abrir nuevas vías de acceso que conectasen directamente el centro comercial y de negocios previsto con toda la región metropolitana, para crear nuevos espacios para el encuentro, el ocio y la relación, concretados en forma de nuevos paseos arbolados para La Habana Vieja, y para hacer más vistosos los edificios monumentales, al derrumbar las viviendas que los envolvían, esto es, la funcionalidad del espacio por encima de cualquier otra consideración:

«En los albores del año 1955, las condiciones de La Habana eran peores, sus calles angostas imposibilitaban cada vez más el tránsito de los nuevos vehículos motorizados que la industria y el comercio habían traído a la civilización; la ausencia de zonas adecuadas para el parqueo de los mismos hacía dificultoso manejar; el calor y el aumento vertical de las construcciones quitaban mucho a las brisas que antaño refrescaban la ciudad. La falta de parques y lugares de esparcimiento era alarmante ya... Toda la vida económica del País, oficinas del Estado, centros comerciales e industrias se apiñaban unos sobre otros, asfixiando en su atmósfera siempre tensa a todos los que alli desarrollaban sus actividades» (Diego, 1955).

El valor simbólico se potenciaría relegando a un segundo término la gran plaza cívica - la actual Plaza de la Revolución- en beneficio del viejo centro junto al Capitolio, contexto en el que Sert propone la construcción de un nuevo palacio presidencial y centro gubernamental, que debía levantarse entre las fortalezas de El Morro y La Cabaña, junto a la salida del túnel bajo la bahía. El nuevo escenario, en pleno centro histórico pero al otro lado de la bahía, debía ser cabeza de puente para la ocupación de esa ribera, virgen hasta esos momentos, y para su puesta en valor al servicio de los nuevos desarrollos urbanísticos previstos.

La función económica del centro se revitalizaba mediante el diseño de un área financiera en plena Habana Vieja, desarrollada linealmente entre las calles Muralla y Tejadillo, a lo largo de las calles Cuba y Habana, sobre un nuevo espacio especialmente concebido y planeado para acoger esa función específica. El centro recuperaba su papel comercial y de negocios vinculado al puerto. De igual modo, la función turística se potenciaba por la potente ocupación hotelera de todo el frente marítimo del Malecón, desde la fortaleza de La Punta hacia El vedado, y se reforzaba con la recreación de una isla artificial para acoger nuevas instalaciones para el ocio turístico: hoteles, casinos, comercios, tal como hoy recogen las transformaciones de viejos puertos comerciales en nuevas áreas de ocio en todo el mundo. De nuevo, la supeditación del entorno a la eficacia de la función instalada.

La función residencial se mantenía, si bien alterando sustancialmente el escenario físico. En general, se mantenía el trazado y la sección históricos de las calles, salvo en el entorno del nuevo centro financiero y en los nuevos ejes de circulación rápida proyectados: la prolongación hasta el puerto de la Avenida Máximo Gómez (antigua Calzada del Monte) a través de la Calle Muralla y la ampliación de la Calle Habana directamente conectada con el nudo viario del túnel bajo la bahía; también se eliminaban las manzanas entre Lamparilla y Amargura para crear un paseo ajardinado desde el Capitolio hasta el puerto. Más sustancial era la propuesta sobre el espacio edificado, consistente en abrir el interior de las manzanas 


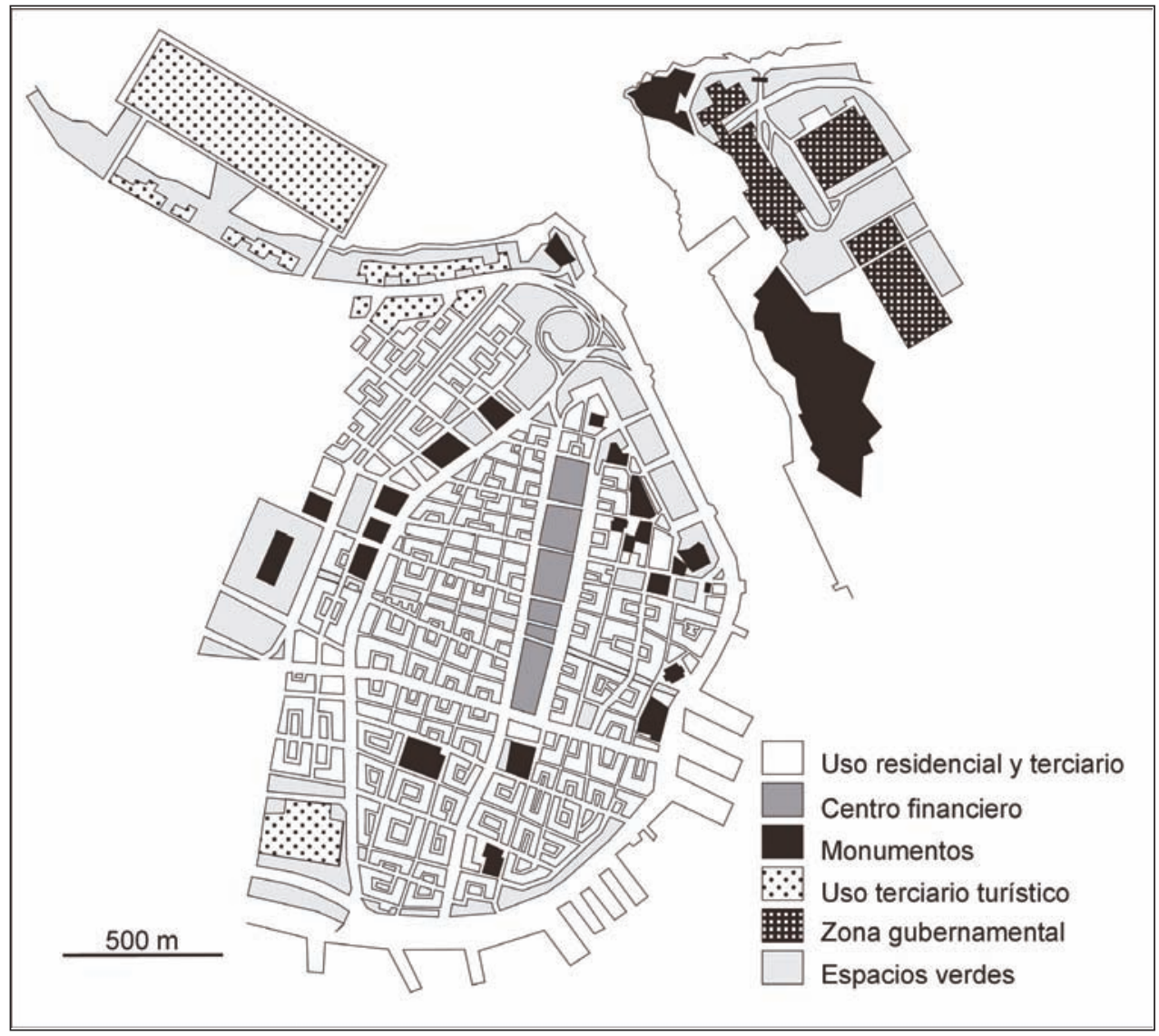

Figura 2. Propuestas del Plan Director de La Habana de Sert, 1955-1958, para el centro histórico de la ciudad (fuente Archivo Histórico Nacional - AHN—, dibujo G. Ponce).

del centro histórico, mediante pasillos de acceso desde las calles. Se conseguía, de ese modo, mayor superficie de fachada, áreas peatonales, pequeños espacios ajardinados al abrir los huertos y patios interiores a la calle, y nuevas parcelas para la construcción de nuevos edificios exentos - al gusto del Movimiento Moderno - para oficinas y viviendas.

Las actividades industriales debían limitarse en el viejo contexto de la bahía, afectada por los procesos de transformación en un espacio de nueva centralidad. Se mantenían algunas actividades muy vinculadas con el puerto - como las refinerías y los almacenes - pero se proponía su alejamiento y la creación de nuevas ciudades satélites para alojarlas, en una órbita situada entre los $30 \mathrm{~km}$ y $50 \mathrm{~km}$ de distancia respecto del centro. Esos nuevos asentamientos urbanos debían, además, acoger las residencias de los obreros empleados en las plantas de producción y, por consiguiente, estar dotados de equipamientos específicos para la familia, tales como centros de educación, jardines y zonas deportivas y centros comerciales y de relación.

En ese sentido, se daba el paso cualitativo desde las pequeñas manzanas parceladas, a las supermanzanas, consideradas como unidades colectivas de proyecto para la convivencia 


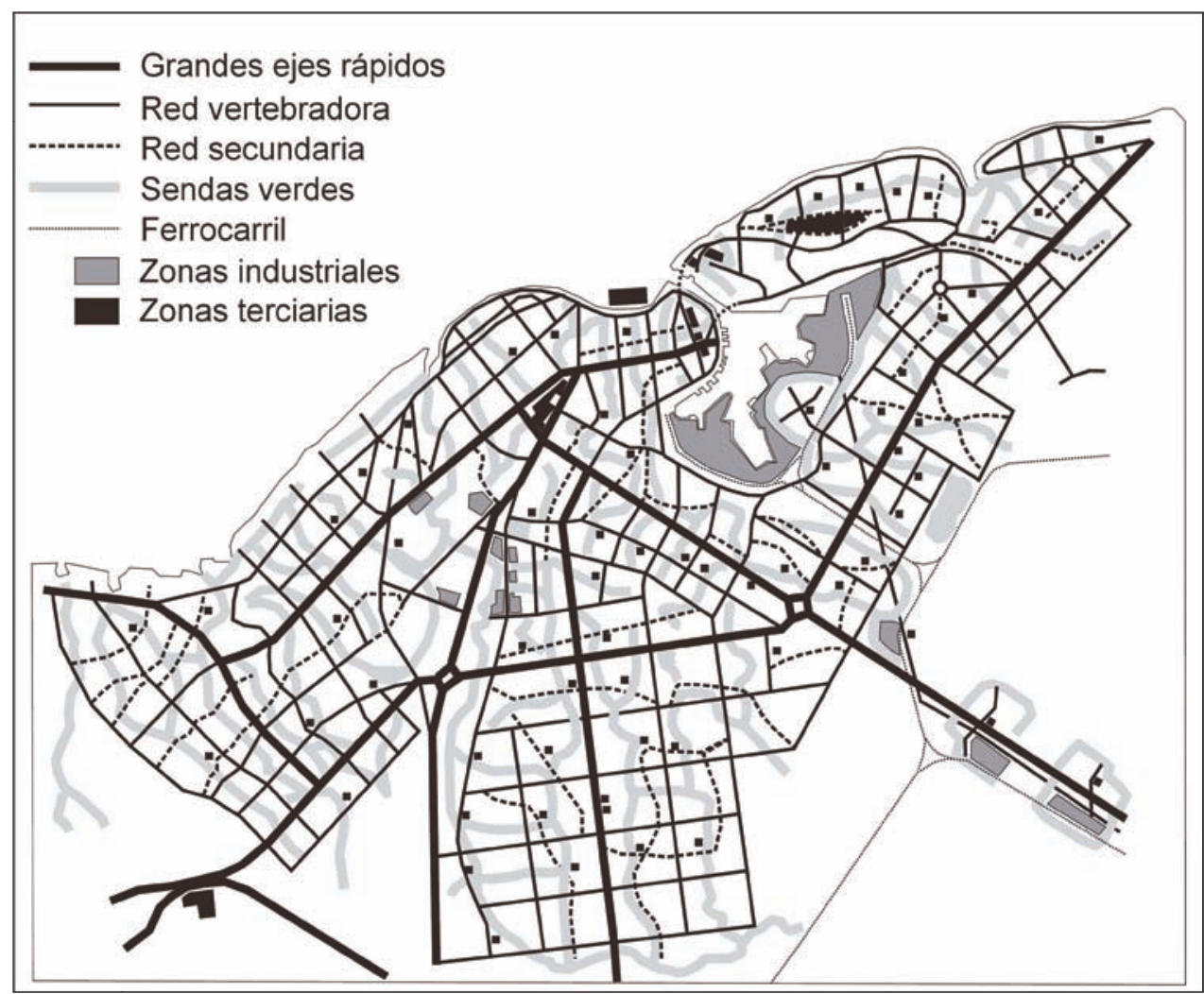

Figura 3. Plan de Paul Lester Wiener, José Luis Sert, Paul Schulz, Mario Romañach y otros, 1958 (fuente A.H.N., dibujo: G. Ponce).

de millares de personas. Las propuestas de Sert y Wiener para La Habana del Este recogían esa idea de ciudad satélite, organizada en supermanzanas concebida como célula urbana o célula-pueblo, también denominadas unidades vecinales, donde las viviendas en bloques colectivos giran alrededor de un centro de servicios para la comunidad.

Más compleja resultaba la aplicación de esas ideas a la ciudad consolidada, donde el principio de propiedad privada era mucho más fuerte y donde el valor del suelo ya construido hacía difícil la demolición de las viviendas. Con todo, el plan proponía ajustar la idea de la supermanzana al viejo entramado callejero resultante de los sucesivos repartos. Para ello se perfilaban grandes unidades urbanas, resultado de la agrupación de las viejas manzanas en nuevas unidades de planificación, con el objetivo de introducir en ellas los mismos equipamientos definidos para las unidades vecinales de las afueras. Las nuevas células urbanas en el viejo entramado eran delimitadas por vías rápidas de comunicación, que debían servir de enlace con el resto de la ciudad. No obstante, las calles internas quedaban sometidas a procesos de control de la velocidad y a la peatonalización selectiva, conforme con unos flujos de radio mucho más corto y de carácter estrictamente local (dentro de la célula). En ese sentido, el plan contemplaba la creación de largos pasillos verdes de conexión entre las células urbanas, tanto para hacer posible los desplazamientos 
a pie, como para dotar al denso centro de La Habana de nuevos espacios verdes a modo de dilatados parques lineales.

La nueva ciudad de alcance regional debía contar con una nutrida y fluida red de comunicaciones. Para ello, era preciso deslindar los diferentes flujos conforme con su funcionalidad, estableciendo una precisa jerarquía. De ese modo, al servicio de los grandes trayectos se proponían grandes vías rápidas de acceso desde la periferia hacia el centro y, también, entre los distintos repartos de la ciudad consolidada. Las comunicaciones entre repartos se agilizaban mediante otros conductos de segundo nivel. Por último, dentro de cada célula urbana se redistribuían los flujos rodados y peatonales mediante una malla más fina de calles.

Si hasta esos momentos las propuestas urbanísticas giraban en torno a la necesidad de remodelar y embellecer el escenario físico, así como sobre el problema de la accesibilidad en automóvil, el Movimiento Moderno, apoyado por los más destacados urbanistas cubanos, y concretado en el plan de Sert y Wiener, proponía la sustitución de los modelos formales por nuevos modelos funcionales. Las nuevas teorías urbanísticas, apoyadas en un gran despliegue tecnológico, pretendían tener validez universal y estar, por ello, fuera de tiempo y lugar. El programa urbanístico se concretaba en un plan director integral, compendio de todos los aspectos, pretendidamente suficiente para lograr la reactivación económica y la mejora de las condiciones de vida de La Habana, elaborado por expertos y por ello indiscutible. La eficacia era objetivo principal, y a ella se supeditaban los demás aspectos (la vida social, el medio ambiente y el patrimonio).

Bajo esos preceptos, el plan de La Habana proponía la conversión de una vieja, extensa y compleja ciudad capitalista en una eficaz máquina capitalista. Los negocios y la burguesía recuperaban el centro, expulsando de él las actividades menos poderosas y, con ellas, a los segmentos sociales más desfavorecidos. El dogma de la zonificación exigía planificar espacios para acoger actividades específicas, y distribuirlos por el territorio según su capacidad de generar beneficios. Así, la función turística hacía acopio del litoral y de los mejores paisajes, seguida por las áreas residenciales de las clases sociales con mayor poder adquisitivo. Mientras la industria se expulsaba hacia el exterior de la ciudad, arrastrando con ella, por pura lógica capitalista, la mano de obra y sus residencias. No era la dictadura de Batista el marco adecuado para el desarrollo de los programas sociales vinculados al pensamiento moderno, ni para el despliegue de los programas de equipamientos y servicios contenidos en el plan. Tampoco lo fue el escenario surgido tras la Revolución, que identificaba ideológicamente el modelo propuesto con el paradigma del sistema capitalista y, más en concreto, con la penetración norteamericana en la escala de valores sociales, culturales y, por supuesto, económicos, de forma que esos planes modernos nunca fueron acometidos.

\section{La «ciudad moderna» de La Habana del Este}

En 1955, la Compañía Urbanizadora Anacaona S.A. presentaba la primera gran promoción de carácter unitario para uso residencial (sin el carácter turístico de otras promociones en las Playas del Este). Se trataba del Residencial Vía Túnel «primer residencial de una ciudad planeada de acuerdo con la nueva ciencia urbanística, que brindará una vida más cómoda, con todos los adelantos de la moderna civilización», en clara alusión a las ideas urbanísticas del Movimiento Moderno, «que será la solución al problema del tránsito, la aglomeración y la vida incómoda que padecen los que viven en la capital» (Diego, 1955). Imbuidos en las supuestas excelencias de la vida motorizada y de la ciudad de muy baja densidad, los promotores se publicitaban demagógicamente como salvadores de la ciudad: 
Entonces fueron los propietarios de La Habana del Este los que, uniendo sus esfuerzos a hombres de empresa, pusieron en plano de actualidad el viejo proyecto de unir La Habana, poblada en demasía, con sus tierras todavía vírgenes ... en esta gran obra, que está llamada a ser de inmensa utilidad para el bienestar, progreso y salud del pueblo cubano (Diego, 1955).

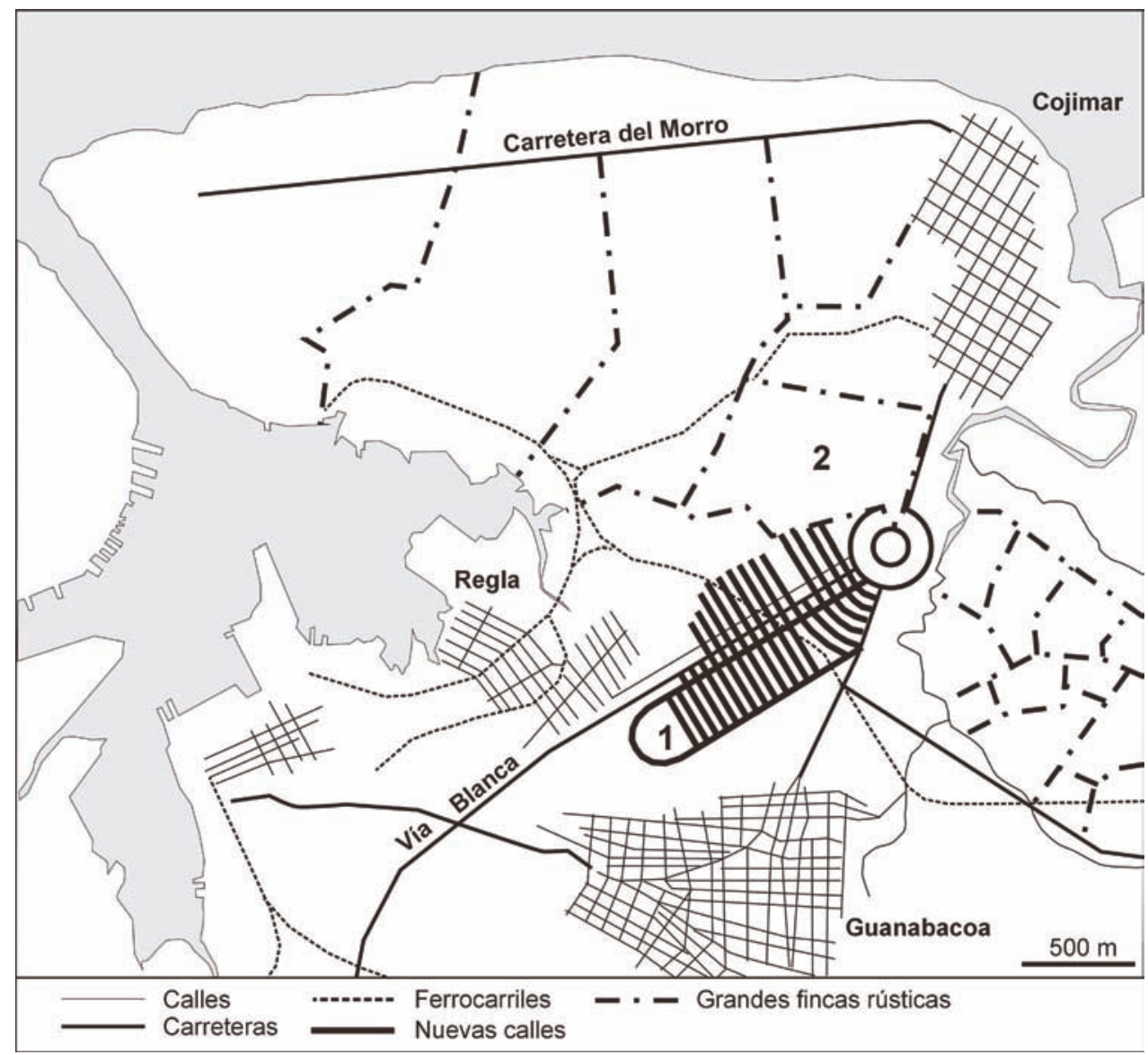

Figura 4. La Habana del Este en 1955. Se observa el tamaño de las grandes fincas asentadas sobre el suelo pobre desde el punto de vista agrícola del paraje de El Morro, en contraste con las fincas de tamaño medio de la zona agrícola del Valle del Río Cojímar, al Este de Guanabacoa: 1, Parque Residencial Bahía (actual reparto de Eduardo Chibás); 2, finca prevista para la ejecución del reparto Residencial Vía Túnel (actual reparto Antonio Guiteras), ambas promociones gravitan sobre la nueva centralidad creada por la Rotonda de Cojímar o Plaza del Este (fuente AHN, dibujo G. Ponce).

El túnel bajo la desembocadura de la bahía sustituía al viejo proyecto de 1912 de construcción de un gran puente, conforme con las posibilidades técnicas del momento. En 1949, desde el Ministerio de Obras Públicas se proponía la construcción de un túnel desde las 
esquina de Virtudes y Prado — en la orilla occidental del canal de la bahía — hasta detrás de la fortaleza de La Cabaña — en la orilla oriental del canal—. Desechado el proyecto por sus afecciones sobre el paseo del Prado y alrededores, en 1954 se planteaba otro proyecto, sobre la misma idea de un túnel, pero más ajustado al entorno urbano, que comenzaría a ejecutarse en los años siguientes por la Societé des Grands Travaux de Marseille. El proyecto contemplaba la construcción de dos grandes tubos en paralelo, cada uno con unos 600 metros de longitud entre una y otra orilla, con 22 metros de sección y 7 metros de altura, que dejarían sobre ellos un canal navegable de 45 pies de profundidad, suficiente para embarcaciones de gran calado. Esto es, colosal obra pública suficiente para acoger los grandes flujos previstos desde la ciudad consolidada hacia los «cinco millones de metros cuadrados» que esperaban ser ocupados en el macroproyecto de La Habana del Este.

La compañía promotora, amparada en la concesión otorgada por Ley-Decreto $n^{\circ} 1550$, de 4 de agosto de 1951, se arrogaba los derechos de peaje que debía producir el túnel, y el repartimiento legal de los terrenos situados en la Zona General de Influencia del Túnel. Se producía la conjunción de intereses de los propietarios del suelo, de los promotores urbanísticos, de la empresa constructora del túnel y del Banco de Comercio Exterior, para financiar un proyecto que, según presupuesto, se elevaba a 35 millones de dólares.

Las iniciativas individualizadas se sucedían ante la oportunidad de negocio en los territorios de La Habana del Este puestos al servicio del desarrollo urbanístico por las nuevas infraestructuras de comunicación. El Plano Regulador de La Habana del Este, aprobado por Consejo de Ministros el 27 de enero de 1955 proponía, sin embargo, una concepción unitaria de todo el espacio situado al oriente de la Bahía. Plenamente imbuido en los paradigmas del urbanismo racionalista, la propaganda oficial señalaba:

«La Habana del Este, tercera ciudad en el mundo que se planifica antes de ser habitada, estará dividida en zonas, una Zona Industrial, alrededor de la Bahía de La Habana; una Zona Comercial, a la izquierda de la Vía Monumental del Túnel; Zona Residencial, frente a la costa norte de la isla y Zona de Oficinas, que se encuentra a la salida del Túnel y será dedicada exclusivamente para edificios gubernamentales y oficinas de otro tipo» (Diego, 1955).

La Habana del Este, concebida como una ciudad autónoma, separada de la vieja ciudad, proponía acoger a unos 200.000 habitantes, conforme con el crecimiento esperado de la región urbana de La Habana, unos 600.000 habitantes en el periodo 1955-1975 según proyecciones de la propia promotora.

\subsection{La influencia de los CIAM en el macroproyecto}

La «modernidad» del nuevo planteamiento se fundamentaba en la disgregación espacial de los diferentes usos, siguiendo el modelo de la Ville Radieuse (1933) de Le Corbusier y los postulados de la Carta de Atenas (1933-1942), donde se establecía que cada una de las cuatro funciones fundamentales de la ciudad (habitar, trabajar, circular y recrearse) debían diseñarse de forma específica excluyéndose entre sí.

Los redactores del Plano de La Habana del Este pudieron tener bien presente el manifiesto del VIII Congreso Internacional de Arquitectura Moderna (CIAM), celebrado en 1951, dedicado al «Corazón de la Ciudad». En él se recogía la nueva teoría del urbanismo moderno que, en sus aspectos fundamentales, proponía la búsqueda de un emplazamiento singular, con paisajes atractivos, como eran los territorios de La Habana del Este, convenientemente alejado de la vieja e inservible ciudad histórica. De igual modo, el Plano de La Habana del 
Este sigue los principios de la edificación abierta, las grandes praderas y espacios abiertos, sustitución de la plaza tradicional por grandes corredores verdes que dan cohesión a la nueva ciudad y una manifiesta separación, conforme con Le Corbusier, del centro más representativo de la ciudad - la zona gubernamental — de la zona comercial y de ocio. Como en La Habana del Este, la nueva monumentalidad de esos centros simbólicos debía generarse por la envergadura de los edificios — rascacielos- y por su diseño moderno.

Para organizar las diferentes zonas funcionales se suprime la calle corredor por una compleja jerarquía de viales, cada uno de ellos con una funcionalidad específica (desde las autopistas rápidas hasta las sendas peatonales, trazadas a diferente nivel para eliminar los cruces), en un esquema que potencia la movilidad individual en automóvil. La influencia de los CIAM en La Habana del Este queda reflejada incluso en el nombre asignado a la principal arteria estructurante del complejo — la Vía Monumental—, y en la secuenciación de los viales que, de acuerdo con el IV CIAM (de 1948), contaba con autopistas, vías provinciales, vías urbanas, vías parque, vías comerciales, vías de sector, vías de acceso local y vías peatonales o sendas.

La función de circular quedaba así expresamente resuelta mediante las grandes infraestructuras viarias. La gran artería, la Vía Monumental, era diseñada como una doble vía de circulación rápida, con unos 7 km de longitud y unos 150 metros de sección (mientras la $5^{\text {a }}$ Avenida en Miramar, la calle más amplia de La Habana en el momento, contaba con 38 metros de sección) que, a través del túnel por un lado, conectaba «en 30 segundos» con el centro de La Habana, mientras que hacia oriente, engarzaba con la red estatal de carreteras -Vía Blanca, Carretera Central-.

La propuesta de establecer una nueva Zona Gubernamental en los territorios del Este sería recogida también por el Plan Director de La Habana de Sert (1955-1958), si bien ubicado junto al fuerte de La Cabaña, en un lugar de mayor valor simbólico y en posición dominante sobre la vieja ciudad de la orilla opuesta de la bahía (la acumulación de propuesta en esos momentos es evidencia clara del interés especulativo que los inicios de la construcción del túnel comenzaban a despertar).

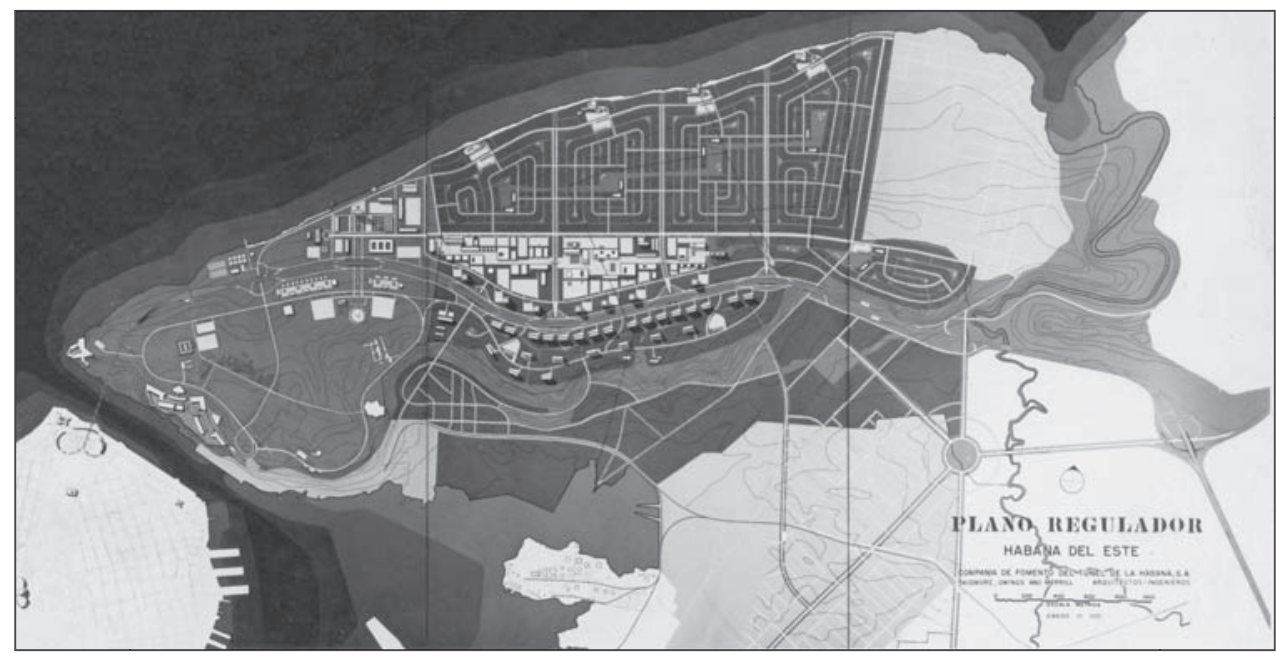

FIgura 5. Plano Regulador de La Habana del Este, 1955 (fuente AHN). 


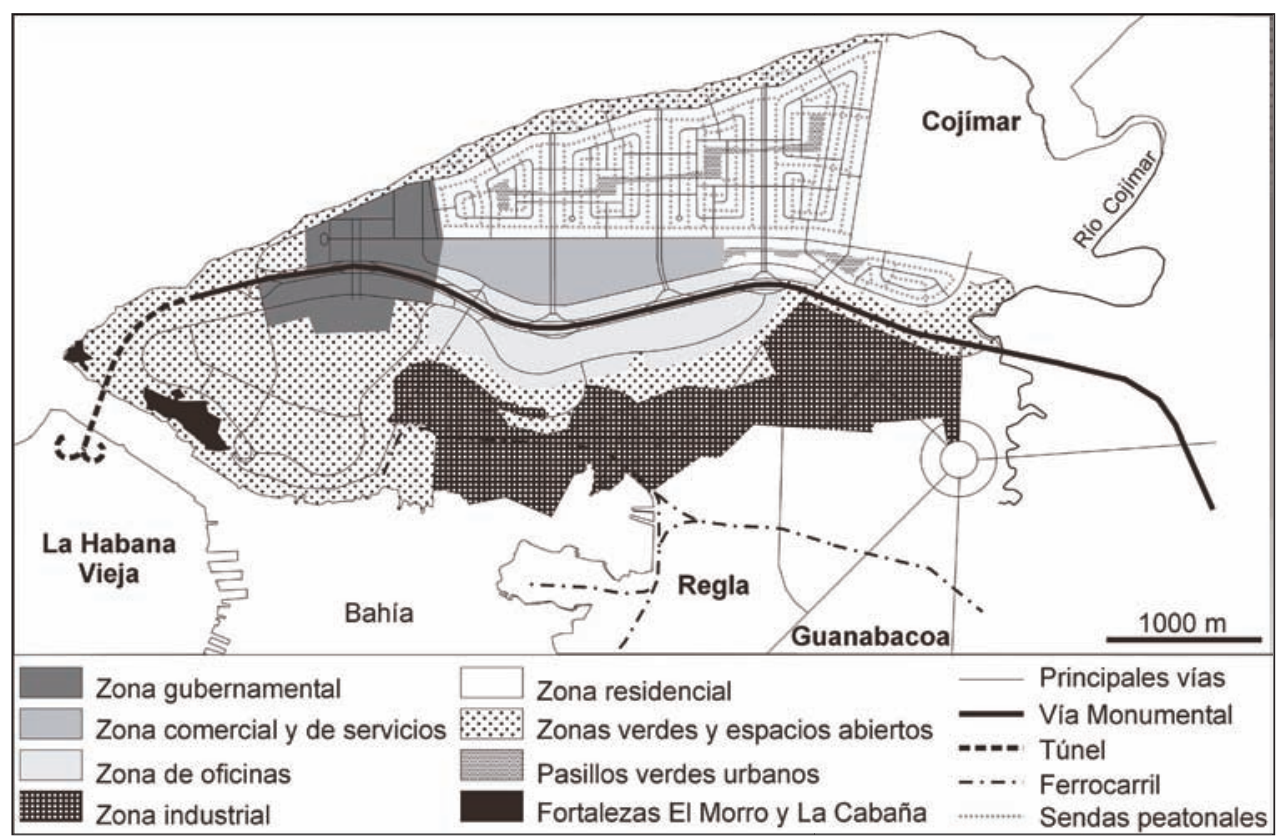

Figura 6. Plano Regulador de La Habana del Este (1955). Las cualidades paisajísticas y la concentración de la propiedad en unas pocas manos hicieron posible la propuesta unitaria, conforme con los criterios racionalistas. Si bien pronto surgieron modificaciones especulativas que fraccionaron e invalidaron sustancialmente el modelo (fuente AHN, dibujo G. Ponce).

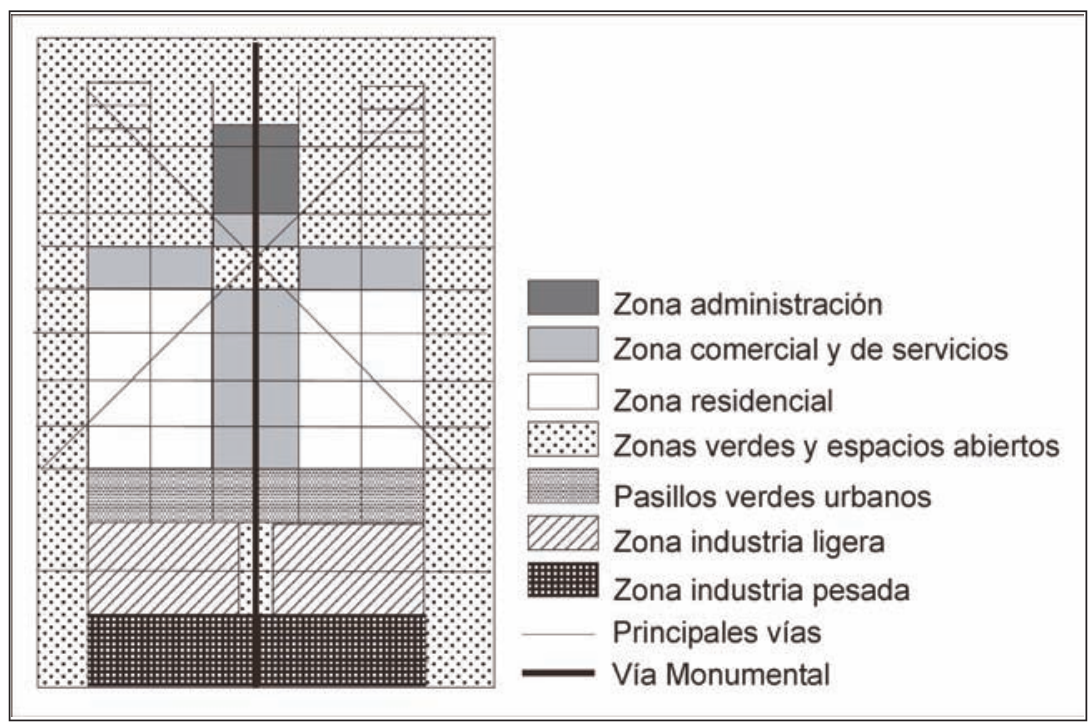

Figura 7. La Ville Radieuse (1933), propuesta de Le Corbusier para la distribución zonal de los diferentes usos del suelo en la ciudad, conforme con un modelo antropomorfo (cabeza, cuerpo y extremidades) que seguiría el Plano Regulador de La Habana del Este en 1955 (Fuente, CIAM, dibujo G. Ponce). 
Esa idea de una zona exclusiva para alojar las principales sedes del poder civil supone la cristalización teórica de las ideas utópicas del Movimiento Moderno, orientadas a la búsqueda de una nueva monumentalidad simbólica del poder civil merced al diseño del plano más que a la factura de los edificios. La concepción autónoma del centro representativo busca alejarlo del bullicio y la distracción del centro comercial y de negocios. La idea defiende el modelo de la acrópolis frente al foro pergeñado por el apretado callejero y la mezcla de funciones de La Habana Vieja. El diseño unitario de la zona pretende establecer una idea de equilibrio entre los tres poderes: palacio del gobernador, parlamento y tribunal de justicia, distribuidos entre grandes praderas, idea plasmada casi de forma coetánea en el plano de Brasilia (1957-1960) y en su Plaza de los Tres Poderes, criticada, por sus detractores, por exceso de monumentalidad, predominio de los espacios vacíos, alejamiento social y abstracción metafísica del espacio urbano.

\subsection{La célula vecinal como unidad básica de la composición}

Si la primera función de una ciudad es la de habitar, conforme con el pensamiento racionalista, la Zona Residencial de La Habana del Este exigía las mayores atenciones en el diseño. Para el Movimiento Moderno, la tarea esencial del urbanista era la de formar organizaciones urbanas «donde sean satisfechas las exigencias materiales y morales de cada individuo y de las sucesivas agrupaciones de individuos en familias, grupos de familias, comunidades, colectividades y poblaciones» (Rigotti, 1967: 391). Para ello, la plasmación física ideal era la de muy bajas densidades en edificios abiertos y distribuidos libremente por extensas praderas «en las cuales el espíritu colectivo no sofoque nunca, sino que, al contrario, exalte el espíritu individual», aspecto que se compagina con la idea de igualdad y nivelación social, plasmada en un diseño uniforme de los espacios residenciales, donde todos los habitantes disfruten en igualdad de condiciones de los servicios y equipamientos para la colectividad.

Para conseguir esas mismas condiciones de hábitat, en La Habana del Este, conforme con los principios racionalistas, la zona residencial se organizaba en cinco grandes células residenciales —o supermanzanas - en las que la distribución de las viviendas se hallaban siempre en un radio accesible desde el centro de las manzanas donde se establecían los equipamientos y servicios propios de comunidad: centros docentes, sanitarios, deportivos, bomberos y policía, sociales y de relación, con escala de barrio y bajo el principio de promover los desplazamientos a pie. De ese modo, junto a la red vial para el automóvil se establece en paralelo otra red de sendas peatonales que, junto a un complejo sistema de zonas verdes entrelazadas, debían otorgar el carácter más humano al asentamiento. Además, en La Habana del Este, se elegía para esa función los terrenos más elevados y de mejor ambiente y paisaje.

La gran Zona Comercial se articulaba en dos grandes unidades, a uno y otro lado de la principal vía de comunicación — la Vía Monumental- Para el Movimiento Moderno la fuga de las actividades comerciales y de ocio del centro urbano era una consecuencia lógica de las carencias de la ciudad histórica. Por tanto, en La Habana del Este se proponía un vasto complejo terciario, servido por unos $4 \mathrm{~km}^{2}$ de aparcamientos, directamente conectado con las vías rápidas de circulación, con el objeto de atraer clientes de paso o de fuera de la macrourbanización. Por su parte, los residentes podían acceder a través de la densa red de sendas peatonales y zonas verdes, con continuidad por el interior de la zona comercial a través de calles peatonales y plazas públicas, organizadas siempre a diferente nivel que las vías de tráfico rodado, para evitar los cruces. 
Segregadas ya las altas funciones representativas del poder civil, la nueva zona comercial insistía en la zonificación específica de, por un lado, las oficinas, servicios a las empresas y centros directivos de empresas, ubicados al sur de la Vía Monumental, en contacto directo con la vasta zona industrial de la orilla de la bahía y, por otro lado, de la zona comercial, de servicios y de ocio pensada también para la población residente y para captar flujos procedentes de otros ámbitos, merced a la enorme accesibilidad rodada.

Por último, el diseño de una ciudad unitaria como La Habana del Este contemplaba también los espacios para la actividad productiva, debidamente separados de las otras funciones por un cinturón verde. En el proyecto se mantenía la vocación industrial de las márgenes de la bahía y se proponía el acondicionamiento de toda la Ensenada de Marimelena, desde las instalaciones de la Estándar Oil en Regla hasta Casa Blanca, en unos terrenos surcados ya por trazados ferroviarios y carreteras al servicio de la actividad industrial. El nuevo concepto de zona industrial contemplaba una serie de grandes equipamientos e infraestructuras ahora de carácter colectivo (frente al carácter privativo de las instalaciones industriales anteriores), de diques, muelles, viales, trazados ferroviarios y otros equipamientos específicos. Excluidas las funciones residencial y comercial, la zona se planeaba como un auténtico polígono industrial, con grandes manzanas capaces para absorber grandes edificios fabriles y modernas plantas industriales, unidas a grandes espacios libres necesarios para maniobra, almacén y movimiento de vehículos industriales. Como siempre, la solución dada mediante el alejamiento del espacio productivo iba en menoscabo de los desplazamientos a pie. Si el proyecto contemplaba la vinculación andando del centro comercial con la zona residencial, los trayectos residencia-trabajo necesariamente debían ser motorizados.

El sistema de equipamientos y servicios se completaba con la suficiente dotación de agua potable. Estimada la demanda diaria en unos $90 \mathrm{~m}^{3}$ (unos 450 litros/habitante teniendo en cuenta la existencia de otras actividades — comerciales, servicios e industriales-), la promotora señalaba haber resuelto el abastecimiento mediante un pozo en la finca Cubeiro de Cotorro y mediante un nuevo acueducto. La red de alcantarillado y de pluviales debía ser conectada con una planta de purificación antes de su vertido, mientras que por LeyDecreto $n^{o} 2025$ se hacía concesión del suministro de energía eléctrica a un precio mínimo. Por último, se proponía un sistema de incinerado para las basuras, como la «solución más moderna» del momento.

En síntesis, un proyecto moderno, coherente con su época, completamente imbuido en las ideas racionalistas, afectado no obstante desde sus inicios por el despertar de intereses especulativos que fraccionarían el concepto unitario. Con el triunfo de le Revolución se pondría fin al proceso urbanístico concebido como empresa capitalista y se transformaría sustancialmente el proyecto, aunque manteniendo buena parte del ideario racionalista: nivelación social, accesibilidad a los servicios en las células residenciales, disposición libre de los edificios en busca de las mejores condiciones de luz, brisas y vistas, cuidado diseño paisajístico y recreación de las condiciones ambientales para una vida más digna y feliz.

\section{El giro revolucionario de La Habana del Este}

Recién abierto el túnel, el triunfo de la Revolución supuso el freno a los procesos individuales de promoción privada y la asunción por parte del nuevo Gobierno, conforme ahora con los nuevos presupuestos ideológicos. El Gobierno revolucionario, a través del Instituto Nacional de Ahorro y Vivienda, propondría un cambio radical en la concepción del nuevo espacio urbano, también inspirado en las propuestas sociales y formales del Movimiento Moderno, mediante el empleo de modernas técnicas de construcción masiva, para la construcción de un prototipo de unidad vecinal, exportable a otras partes del País. 
El proyecto fue declarado de interés social para el desarrollo del plan de vivienda, y debía contener en sus aspectos formales todo un nuevo ideario social y urbanístico.

El primer desarrollo se ubicó a 2'5 km del centro de la ciudad, conectado por la nueva autopista, la Vía Monumental, que daba continuidad a la Vía Blanca de trazado perimetral en torno a la bahía. Los terrenos fueron expropiados de acuerdo con el nuevo marco legal y los objetivos orientados hacia la creación masiva de viviendas para obreros que, de ese modo, se beneficiarían por vez primera de hogares en un emplazamiento privilegiado, junto al mar, levantados en un entorno urbanísticamente avanzado y bien dotado que, por su condición de barrio aislado, debía contener muchos equipamientos autónomos, como guarderías infantiles, escuelas primarias y secundarias, círculos sociales, centros de salud, centros administrativos, centro comercial y zonas deportivas, como complemento imprescindible para 8.000 habitantes que debían alojarse en 1.306 viviendas levantadas en las afueras.

El modelo ejecutado responde a las influencias claras de la célula urbana o unidad vecinal cuyo objetivo es la resolución masiva de un hábitat de calidad, al agrupar un contingente humano sobre un núcleo de servicios colectivos que, por proximidad de sus usuarios potenciales, alcanzan la optimización de sus funciones. La población instalada, limitada necesariamente en su número por la dimensión de los servicios creados, halla en el entorno urbanizado las condiciones apropiadas para mantener una intensa vida colectiva, en un escenario que potencia la cohesión social. El orden interno se ajusta a la premisa de máxima eficacia en las distancias, para que los recorridos sean mínimos. En La Habana del Este, la unidad vecinal se estructura en siete grupos primarios residenciales, de unas 200 viviendas en edificios de cuatro u once pisos. Al igual que en la propuesta original de Perry (Rigotti, 1967: 347-363), cada grupo residencial tiene por centro una plaza donde se instalan los servicios infantiles (parques, jardín de infancia, guarderías), y la unidad vecinal en su conjunto tiene por centro los centros de enseñanza y las áreas deportivas.

Según el modelo, todos los recorridos deben estar contemplados en un radio máximo de 400 m, y en La Habana del Este se estableció un radio de acción máximo de $150 \mathrm{~m}$ para cada conjunto residencial, favorecido por la construcción en altura y una densidad elevada para la época de 55 viviendas por Ha, contrarrestada empero por la liberación de suelo para usos comunales que potencian el encuentro y la cohesión, frente a los jardines y patios privados de la ciudad tradicional. El modelo proponía la potenciación de la vida colectiva frente a la vida individual.

En el interior de la célula no debe existir tráfico rodado; la circulación debe ser perimetral con accesos restringidos hacia el interior por calles en fondo de saco, calibradas para tráfico muy reducido. En la práctica, se trata de un modelo urbano diseñado a la escala del automóvil, que aprovecha al máximo las vías rápidas de acceso (la Vía Monumental hacia el centro y la Vía Blanca hacia las zonas industriales), pero luego cercena al máximo la circulación interna, como actividad molesta y peligrosa. Para las funciones especializadas, la célula depende del centro de la ciudad, mientras los puestos de trabajo deben hallarse fuera, pero próximos.

El orden externo, o la forma de agrupar las diferentes unidades vecinales entre sí y con el resto de la ciudad, sigue un modelo geométrico de agrupación, que supera la cuadriculada característica de los repartos anteriores y experimenta con nuevas formas de conexión entre las grandes manzanas, que adopta una malla flexible de elementos repetidos a lo largo del eje axial de la Vía Blanca. La Unidad Vecinal $n^{\circ} 1$ adopta la forma de pentágono, al que deben conectarse otros sin solución de continuidad, conforme con el axioma de que cuando una unidad vecinal se satura se construye otra.

A la ventaja de la adecuada relación tiempo-desplazamientos en el interior de la célula, la forma pentagonal permite trazados perimetrales con ángulos más abiertos que el de $90^{\circ}$ 


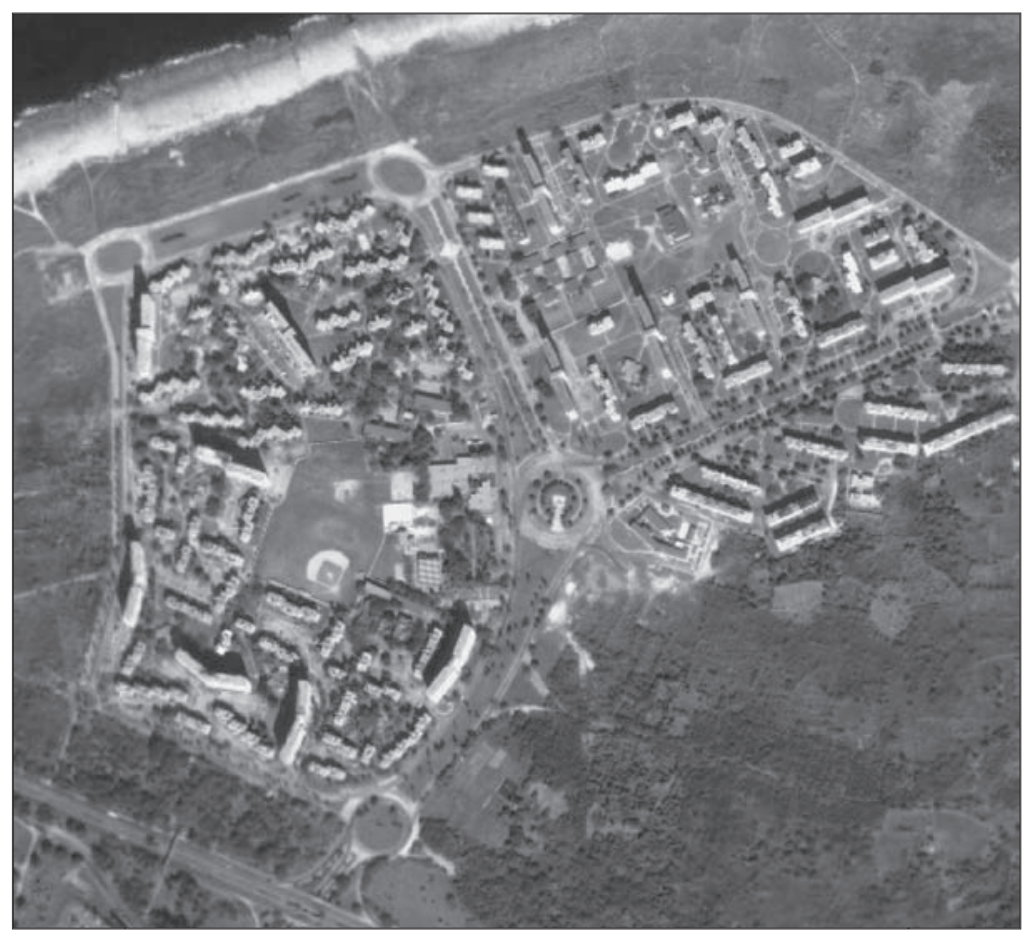

Fото 1. Vista aérea de La Habana del Este, a la izquierda, la Unidad Vecinal $n^{\circ} 1$ ya su derecha una nueva unidad vecinal. Se observan las zonas deportivas centrales, la resolución volumétrica mediante edificios de 4 y 11 alturas, las segregación de flujos mediante sendas peatonales y calles que acaban en grandes aparcamientos (fuente Google Earth, 2006).

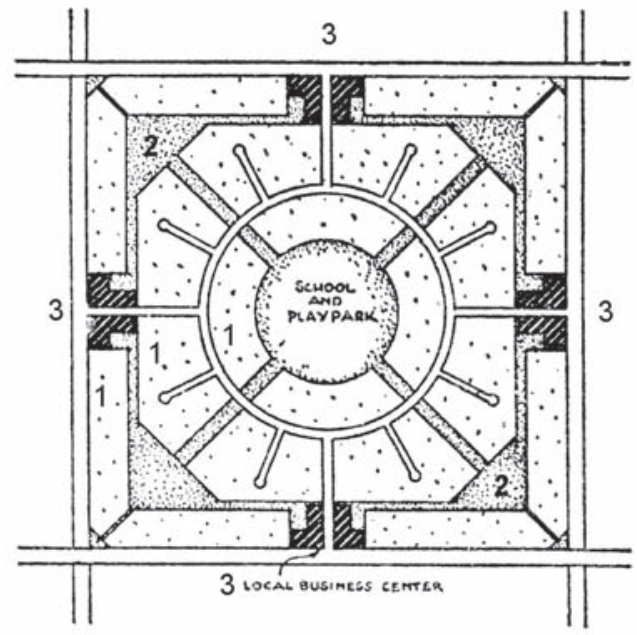

FIGURA 8. Esquema teórico de una unidad vecinal estructurada alrededor de un núcleo central configurado por el centro de enseñanza y los campos de juego: 1, zonas residenciales; 2, zonas verdes; 3 , centros colectivos (comercio, administración, salud, etc.) (fuente Rigotti, 1967, elaboración propia). 


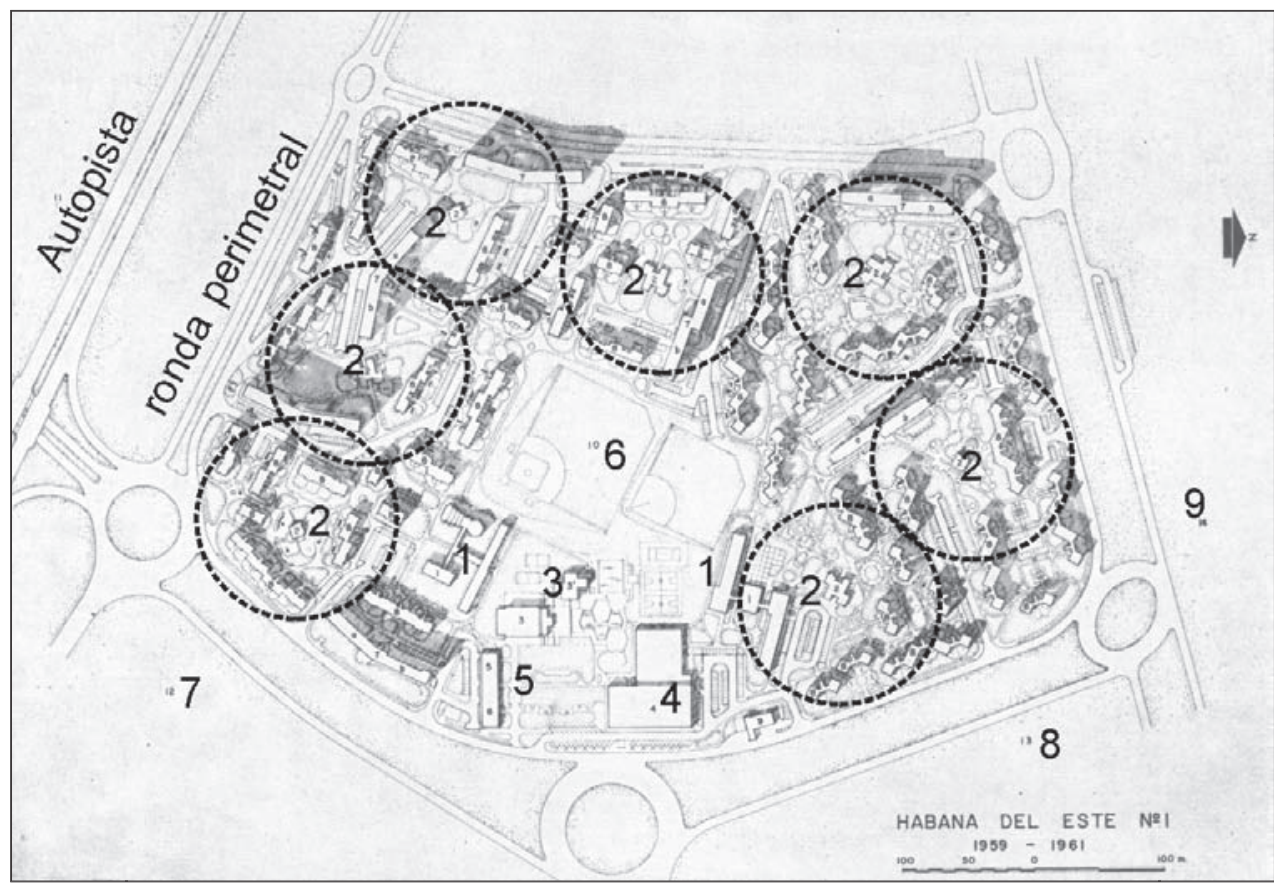

Figura 9. La «célula urbana» de La Habana del Este, 1959-1961: 1, escuelas primarias y secundarias; 2 , centro de educación infantil y radio de $150 \mathrm{~m}$; 3, círculo social y club; 4, centro comercial central; 5, centro de salud y centro administrativo; 6, zonas deportivas; 7, Unidad Vecinal $\mathrm{n}^{\circ} 2$ (proyectada); 8, Unidad Vecinal $\mathrm{n}^{\circ} 3$ (proyectada); 9, Unidad Vecinal $\mathrm{n}^{\circ} 4$ (proyectada) (fuente UIA, 1963, elaboración propia).

que confiere la forma cuadrada, por consiguiente los desplazamientos son más cómodos y rápidos.

En el sentido experimental, La Habana del Este fue un proyecto ambicioso y moderno, pero lejos de las posibilidades reales del País y de los habitantes instalados, seleccionados más por la imperiosa necesidad de vivienda que por su relación trabajo-residencia o por sus posibilidades de movilidad autónoma: tan sólo el 2\% de los adjudicatarios poseían automóvil (UIA, 1963: 103). Sin embargo, desde el punto de vista social constituyó un auténtico logro, al dar empleo y vivienda digna a un elevado número de familias, y desde el punto de vista urbanístico, elaborado como auténtico prototipo de ensayo, marcó las pautas para la futura construcción masiva de viviendas en bloques aislados sobre grandes manzanas, construidos mediante prefabricados.

\section{Bibliografía}

CIAM (1955): El Corazón de la ciudad: por una vida más humana de la humanidad, Congresos Internacionales de Arquitectura Moderna; a cargo de E. N. Rogers, J. L. Sert y J. Tyrwhitt, Hoepli, Barcelona, $183 \mathrm{pp}$.

DIEGO TOUSSAINT, T.E., (1955): Residencial Vía Túnel, Memoria justificativa del programa urbanístico para construir La Habana del Este, original mecanografiado, Archivo Histórico Nacional

HALL, P., (1996): Ciudades del mañana, ed. del Serbal, Barcelona, 494 pp. 
LE CORBUSIER (1935): La Ville Radieuse, Vincet, Freal \& Cia (ed. 1964), Paris, 346 pp.

LE CORBUSIER (1964): Los tres establecimientos humanos, Poseidón, Buenos Aires, 197 pp.

RIGOTTI, G. (1967): Urbanismo. La composición, ed. Labor, Madrid, 610 pp.

SEGRE, R. (1978): Las estructuras ambientales en América Latina, Universidad de La Habana, La Habana, 295 pp.

SEGRE, R. (1988): Arquitectura y urbanismo modernos. Capitalismo y Socialismo, Ed. Arte y Literatura, La Habana, $531 \mathrm{pp}$.

SEGRE, R., CÁRDENAS, E., ARUCA, L. (1981): Historia de la arquitectura y del urbanismo: América Latina y Cuba, La Habana, Pueblo y Educación, 354 pp.

TARCHÓPULOS, D. (2006): «Las huellas del Plan para Bogotá de Le Corbusier, Sert y Wiener», Scripta Nova, Universidad de Barcelona, Vol. X, núm. 218 (86).

UNIÓN INTERNACIONAL DE ARQUITECTOS —UIA-, (1963): La arquitectura en los países en vías de desarrollo. Cuba, UIA, La Habana, 118 pp. 